\title{
Práticas discursivas e produção de sentidos do "patrimônio": o mito da São Luís (MA), a Atenas brasileira
}

\author{
Discursive practices and production of meanings of "heritage": \\ the myth of São Luís (MA), the Brazilian Athens.
}

\section{Conceição de Maria Belfort Carvalho}

\begin{abstract}
RESUMO
O trabalho problematiza a genealogia do conceito de Patrimônio, avaliando os discursos que constroem uma identidade nacional e, como consequências dão forma a especificidades locais, direcionando a produção de singularidades espaciais. Essa problematização embasa a discussão sobre a constituição da identidade de São Luís em torno da figura da Atenas Brasileira, analisa o conceito de patrimônio dela decorrente e a construção do espaço turístico. Esta pesquisa se orienta pela proposta teórico-metodológica da Análise do Discurso de base foucaultiana (GREGOLIN, 2004; SARGENTINI; NAVARRO-BARBOSA, 2004), cujo pressuposto básico é o de que o discurso está articulado ao sujeito e à História e essa articulação revela a própria trama que dá sentido às palavras e às coisas. Procuramos investigar a produção dos sentidos e seus efeitos (GREGOLIN, 2004) a partir de uma genealogia do discurso do patrimônio, por meio da análise de uma propaganda turística e de um folder.
\end{abstract}

PALAVRAS-CHAVE: Discurso; Patrimônio; Identidades .

\section{ABSTRACT}

This paper is aimed at discussing the genealogy of the concept of heritage, assessing the discourses that build a national identity and as a consequence give way to local specificities, directing the production of spatial singularities. This questioning enhances the discussion on the constitution of São Luis identity around the figure of the Brazilian Athens and the analysis of heritage concept resulting from it. This research is guided by the theoretical-methodological proposal of the discourse analysis based on Foucault principles (GREGOLIN, 2004; SARGENTINI; NAVARRO-BARBOSA, 2004), whose basic assumption, shared by many, and defended by Foucault, is anchored in the idea according to which the discourse is articulated to the subject and history and such articulation reveals the scenario that provides meaning to words and things. We sought to investigate the production of the senses, its effects (GREGOLIN, 2004) from the perspective of heritage discourse genealogy with emphasis on the analysis of tourist propaganda and a folder.

KEYWORDS: Discourse; Heritage; Identity . 


\section{Introdução}

A genealogia para Foucault corresponde a uma concepção teóricometodológica cujo objetivo é perscrutar a história. Caracteriza-se como uma crítica radical à chamada história tradicional cujos procedimentos fundamentam-se em princípios metafísicos e teleológicos que primam pela busca da origem. Na concepção da genealogia não existe uma origem a priori e a posteriori dos acontecimentos, pelo contrário, esses acontecimentos são resultado de forças diversas, muitas delas guiadas pelo acaso. Daí na genealogia se falar em proveniência e emergência dos acontecimentos. Nessa visão, qualquer fato histórico pode ser estudado genealogicamente. É o que faz Foucault ao usar a genealogia no campo das discursividades, tratando do discurso da loucura, da sexualidade, dos prisioneiros etc. A genealogia se opõe ao método histórico tradicional, na medida em que seu objetivo é "assinalar a singularidade dos acontecimentos, fora de toda finalidade monótona" (FOUCAULT, 2007, p. 15). Para ela, inexistem essências fixas, leis subjacentes, finalidades metafísicas.

Ao contrário da história que se fundamenta no contínuo das coisas, no progresso e seriedade, a genealogia busca descontinuidades, recorrências e jogo. Ela transita no espaço da superfície dos acontecimentos, nos mínimos detalhes, nas menores mudanças e nos contornos sutis: observada a correta distância, há uma profunda visibilidade nas coisas. Tudo é interpretação e a genealogia conta a história dessas interpretações, criadas e impostas por outras pessoas e não inerentes à natureza das coisas.

Os discursos que constroem a genealogia de "patrimônio" e a preservação da memória cultural foram gestados em diferentes momentos históricos. Particularmente importante nessa constituição foi o século XVIII, marcado pelo pensamento iluminista, momento em que o homem começa a pensar-se como centro do universo, senhor de sua vontade, um período de intensa valorização da razão. O lluminismo abraçou a ideia do progresso - entendido como a passagem da barbárie à civilização, da animalidade à humanidade - e buscou a ruptura com a história e a tradição. O lluminismo foi um dos momentos mais importantes da modernidade e caracterizou-se pela fragmentação do sujeito e por uma incessante busca pelo progresso. (BERMAN (2007) O conceito de progresso alimentado no século XVIII fez brotar um sentimento de desenvolvimento e de felicidade e a crença de que a civilização humana alcançaria em breve a plenitude. O aperfeiçoamento e o avanço da ciência a serviço da humanidade, aliados às conquistas do homem, o elevariam a um nível civilizacional e o distanciariam da barbárie.

Apesar de consolidar-se no século XVIII, no Renascimento a noção de progresso já se manifestava como consciência de ruptura entre a ordem da cultura e a ordem natural, pois implicava a negação da repetição cíclica.

No século XVIII, tal pensamento associa-se à consciência do caráter progressivo do conceito de civilização. Nesse momento, apesar de existirem vozes dissonantes, como a de Rousseau, que problematizou o conceito de progresso de sua época 
destacando "o bom selvagem" e "mau civilizado", a crença no progresso é um dado que se demonstra com a própria história geral da humanidade, marcada pela convicção num progresso linear e ilimitado, que destacaria a passagem de uma condição de imperfeição à perfeição da espécie humana (FALCON, 1989, p. 62). Mesmo no Século das Luzes havia um discurso que não comungava com a perspectiva de que o progresso traria apenas melhorias para a humanidade. As ações progressistas passaram a conotar também ameaça às tradições, ao que era representativo do passado, do perene.

Nessa concepção de progresso, é possível vislumbrar a temática do patrimônio pelo fato de este abranger questões que se relacionam a temas como o da identidade, pois no dizer de Falcon (1989, p. 62), talvez em decorrência de seu próprio dinamismo intelectual, as "Luzes" se saldam por novas ambiguidades: "frente à tese da perenidade da natureza humana, em todos os tempos e lugares, afirma-se o caráter mutável da espécie humana a partir das próprias evidências empíricas". A tomada de consciência perante a relação paradoxal entre perenidade e mudança levará o homem a eleger símbolos que delimitem os traços de sua identidade, numa busca pela afirmação e legitimação da memória, entendida como a seleção de fatos que merecem ser relembrados. Na escolha de elementos que serão concebidos como patrimônio, é estabelecido um jogo de representações que identificam um grupo social. Os primeiros bens eleitos como patrimônio são associados à elite, como por exemplo, prédios de famílias ricas, igrejas (bens religiosos), fortes (representativos do poder militar) etc.

A concepção de patrimônio, enquanto elemento evocativo da memória local e nacional, perpassa as ações preservacionistas, impondo um debate acerca do sentido e do significado que ele adquire no contexto de uma dada sociedade. Torna-se preponderante compreender que, subjacente às tentativas de retorno ao passado mitológico, empreendidas pelos gestores estaduais e municipais, artistas, arquitetos e intelectuais, coexiste um amálgama de interesses políticos, econômicos e valorativos imbricados na forma como os sujeitos concebem e interpretam o patrimônio e a memória digna de ser preservada.

Para Pesavento (2004, p. 39), representações "são matrizes geradoras de condutas e práticas sociais, dotadas de força integradora e coesiva, bem como explicativa do real. Indivíduos e grupos dão sentido ao mundo por meio das representações que constroem sobre a realidade". Nessa visão, o patrimônio passa a ser visto como um sistema de representação de uma sociedade em uma determinada época. As narrativas de construção de uma identidade nacional, por exemplo, utilizam-se de construtos patrimoniais para enaltecer determinados elementos que são considerados importantes a uma determinada coletividade, na tentativa de impor uma identidade.

Nesse processo, a apropriação está subjacente à seleção de um elemento como patrimônio, pois é entendida como: 
uma resposta necessária à fragmentação e à transitoriedade dos objetos e valores. Apropriar-se é sinônimo de preservação e definição de uma identidade, o que significa dizer, no plano das narrativas nacionais, que uma nação torna-se o que ela é na medida em que se apropria de seu patrimônio (GONÇALVES, 2002, p.24).

A construção de discursos sobre o patrimônio na cidade de São Luís emergiu numa tentativa de afirmação de múltiplas singularidades, e na busca pela preservação de marcos simbólicos imbuídos de um caráter de autenticidade. Por outro lado, a configuração de cidade-patrimônio reveste-se também na imposição de um imaginário social, ou seja, de "um sistema de ideias e imagens de representação coletiva que os homens, em todas as épocas, construíram para si, dando sentido ao mundo" (PESAVENTO, 2004, p.43). Em São Luís, esses elementos são gerenciados de forma a tornar-se alvo da atividade turística.

Diferentes discursos marcam a noção de patrimônio em São Luís. São fatos, memórias, narrativas que entram no processo de edificação do patrimônio imaterial na cidade. Neste trabalho cabe investigar acontecimentos e detalhes que se destacam como elementos de base dessa genealogia: o mito da Atenas Brasileira e que constroem ou reforçam a representação da cidade como Patrimônio da Humanidade._Que discursos produziram essas representações, que sujeitos enunciaram, que instituições se envolveram nesse processo? Como esses discursos constroem e mantêm a imagem de uma São Luís singular e turística? Nesse sentido, é pertinente mobilizar alguns instrumentos de análise que possam explicar a construção dessas identidades patrimoniais.

\section{São Luís, a Atenas Brasileira}

A construção de uma das identidades maranhenses assume seus contornos nos deslocamentos discursivos que edificam o mito de "Atenas Brasileira", que aproxima os costumes ludovicenses (adjetivo pátrio dado aos que nascem em São Luís) de uma cultura erudita e institui uma herança cultural de inestimável importância na constituição da identidade ludovicense. Esse discurso se erige a partir de uma prática discursiva que opera no campo da literatura.

Para compreendermos os processos de constituição dessa identidade, faz-se necessário percorrermos parte do itinerário da história do Maranhão. Nosso percurso tem início com a instalação da Companhia Geral de Comércio do Maranhão e GrãoPará, em 1755, que significou o advento de um processo de ativação econômica sem precedentes no Maranhão. Para o intelectual maranhense Dunshee de Abranches (1822, p. 6), essa medida política praticada pelo Marquês de Pombal teria sido a "aurora da prodigiosa opulência e engrandecimento" da Província. Isso porque as operações da Companhia de Comércio promoveram a entrada do Maranhão no mercado internacional em virtude da exportação do algodão. A Companhia mobilizou o co- 
mércio da província, que passou a receber créditos, ferramentas, escravos. Tais intervenções transformaram o padrão de vida da região, até então mergulhada na miséria, na gentilidade, na barbárie, sem uma economia que a sustentasse (MARTINS, 2006).

Quando as operações da Companhia de Comércio começaram a apresentar traços de retração das relações econômicas, emergiu entre os homens de negócio, principalmente entre os lavradores, um discurso nostálgico de exaltação àquele passado de opulência, que apontava a região como uma terra promissora: "[...] ainda hoje, muitos lavradores abastados bendizem a fortuna e a opulência de seus bens que tiveram sua origem naquela época" (ABRANCHES, 1822, p. 7).

Para o historiador maranhense Mário Meireles (2008), ainda no Império a província presenciou o surgimento de uma elite fundiária e de uma nobreza rural que lhe conferiram uma posição de primeiro plano no cenário nacional, nos campos econômico, político e cultural. O Império é destacado por Meireles como um período da Idade do Ouro do Maranhão.

O açúcar passa a configurar também um produto de exportação e irá somar com a riqueza da terra juntamente com o algodão. Esses dois produtos agrícolas irão constituir a base da economia maranhense e vão gerar mais riquezas e mudanças nos costumes cultivados nesse primeiro momento.

No final do século XVIII e nas primeiras décadas do século XIX a cidade de São Luís passou por novas mudanças em seus costumes. Habituada a frequentar as festas que se resumiam às atividades da Igreja e do Estado, a elite ludovicense mudou seus hábitos culturais, impulsionada, conforme dissemos anteriormente, pelo crescimento econômico decorrente do ciclo do agodão e do ciclo do açúcar, que lhe possibilitou um intercâmbio cultural com a Europa, particularmente com a França. Vários filhos da elite foram para a Europa realizar seus estudos. Esse intercâmbio provocou uma mudança nos costumes dos maranhenses, que influenciados pela Cidade-Luz contribuíram para a transformação de uma minoria da sociedade e introduziram costumes franceses, destacando-se o interesse pelos bons modos, pelo refinamento, pela arte, pelas letras (LACROIX, 2008).

Sob influência do modelo intelectual francês, o teatro tornou-se uma das distrações favoritas, com apresentações de temporadas líricas de companhias de teatro italiana e francesa, realização de concertos de piano, de saraus e serões para moças - que até então nem sabiam ler - aprenderem música, pintura e belas artes (ABRANCHES, 1941).

Esse momento de expressividade cultural reflete os ideais de progresso iluminista na medida em que marca o crescimento intelectual do homem maranhense: os filhos de proprietários assumem a condição de homens das letras. Vale lembrar que o momento era marcado por um espírito romântico, reflexo do estilo literário da época.

No ambiente cultural que se criou na cidade prosperam dois grupos literários com destaque nacional. O primeiro, chamado de Grupo Maranhense (que atuou entre 
1832 e 1868) - a Primeira Geração - influenciado por uma mentalidade senhorial e um sentimento aristocrático, inaugurou uma prática discursiva de exaltação das riquezas e belezas da terra natal, e se fundamentará com a Segunda Geração na crença e superioridade do homem maranhense (LACROIX, 2008).

A efervescência cultural na qual mergulhou a cidade de São Luís após a constituição do Grupo Maranhense fez emergir o epíteto de Atenas Brasileira'1. Os intelectuais e homens das letras que surgem em torno da "cidade letrada" ${ }^{2}$ de colonização portuguesa, como a cidade de São Luís - um dos poucos centros de intensa atividade intelectual do primeiro e segundo período imperial brasileiro - são chamados de "atenienses". Segundo Martins (2008, p. 294, grifo do autor), "um modo muito produtivo de compreender o mito da 'Atenas Brasileira' é analisar a construção alegórica ou simbólica do passado de São Luís do Maranhão como cidade letrada. O que está em jogo é a origem de um mito", que se fundamenta no resgate do passado de glórias. O autor acrescenta que "a genealogia da construção simbólica de São Luís como 'Atenas Brasileira' é um mito legitimador do Maranhão oitocentista e de um projeto de literatura nacional, até de nacionalidade". Nesse sentido, a identidade maranhense vai se perfazendo a partir de uma construção que se dá no campo das letras.

Do Grupo Maranhense ressalta-se Manuel Odorico Mendes, Francisco Sotero dos Reis, João Francisco Lisboa, Trajano Galvão de Carvalho, Antonio Gonçalves Dias, Antonio Henriques Leal, Joaquim Gomes de Sousa, aos quais podem ser acrescentados os nomes de Joaquim de Sousa Andrade, o Sousândrade e César Augusto Marques. Outros intelectuais de menor repercussão também são destacados: Lisboa Serra, Almeida Braga, Marques Rodrigues, Vieira da Silva, além de Cândido Mendes de Almeida, Pedro Nunes Leal, Belarmino de Matos, Gentil Homem d'Almeida Braga, Antônio Joaquim Franco de Sá, Francisco Dias Carneiro, Joaquim Serra (VERÍSSIMO, 2003).

Gonçalves Dias é fiel ao sentimento nacionalista em que se ancora o Romantismo. Autor do poema I-Juca Pirama, que destaca o índio como figura representativa da nação brasileira, o poeta se eternizou na Canção do Exílio, reconhecida como um dos poemas de temática mais nacionalista de todos os tempos.

A proclamação da República, a abolição da escravatura, a queda da agroexportação e todas as consequências que resultaram desse processo produzem uma mudança no panorama maranhense e a historiografia registra um ciclo decadentista cultural entre 1894 e 1932.

Intelectuais maranhenses como Miguel Vieira Ferreira e Fábio Alexandrino de Carvalho Reis apontam a sensação de decadência da elite da época (MARTINS, 2006). Ferreira (1866, p. 107-108) destaca um estado de letargia vivida por todos:

O nosso espírito é pouco profundo, o nosso typo é o da indolência e fraqueza mental, e por isso mesmo o da superficialidade; [...] entre nós escreve-se muito, muito se projeta, mas não se escrevem obras, nem se fazem trabalhos desenvolvidos [...]. 
Reis (1877, p. 21-22) conclama a elite regional para um trabalho de mudança do estado em que todos se encontravam:

\begin{abstract}
Accordemos do lethargo emquanto é tempo, pois já nos achamos a dous passos do abysmo; e é preciso transpolo-o ou cair n'elle, o que dirão de nós os nossos vindouros, quando souberem que recebemos dos nossos antepasados este bello torrão prospero e fluorescente e Ih'o legamos empobrecido e decadente, por falta de iniciativa, de actividade e energia?
\end{abstract}

Para uma elite que até então se alimentava de uma tradição de grande efervescência econômica e cultural, era o momento de propor mudanças no sentido de resgatar a glória do passado.

A Segunda Geração, que atuou entre 1870 e 1890, tentou manter a tradição de Atenas Brasileira, por meio de um "rejuvenescimento literário". Ancorada nos princípios republicanos que pregavam, dentre outras coisas, a modernidade, a Segunda Geração testemunha uma negação da herança colonial portuguesa. Os "novos atenienses", como eram chamados os intelectuais da Segunda Geração, consolidaram uma formação discursiva que se perfaz na "ideologia da singularidade", a partir da valorização da fundação francesa da cidade de São Luís. Esse discurso de fundação francesa implica num retorno às origens, ou seja, à fundação da capital, mas ao mesmo tempo significa um salto para o futuro, pois a França simbolizava os novos tempos. Esse discurso torna o homem maranhense singular diante do cenário nacional, já que a capital maranhense é a única reconhecida, oficialmente, como capital brasileira de fundação francesa.

O discurso da singularidade emerge numa época de momentâneo crescimento econômico, que estimulou o luxo, a sofisticação, produziu uma mudança no comportamento da elite maranhense e fez emergir uma mentalidade de superioridade do homem, numa tentativa de manter distante o passado lusitano. $O$ discurso de valorização do homem maranhense é marcado pelo declínio econômico. A consciência de que esse homem gozava da virtude da sabedoria, da excelência e quase exclusividade no panorama cultural brasileiro foi impregnada no imaginário da sociedade local, chegando a alcançar repercussão nacional. Projetado segundo as lentes de um "questionável esplendor, o maranhense sentiu-se superior às populações das outras províncias e procurou buscar uma diferença, ainda que mítica, em suas origens" (LACROIX, 2008, p. 66).

A economia de base agroexportadora, que até então era o alicerce do mercado local, foi inviabilizada por medidas como as inúmeras leis abolicionistas que culminaram na assinatura da Lei Áurea, em 1888. A Atenas Brasileira irá respirar os novos ares trazidos pela industrialização que tomou conta do país, e receberá um novo epíteto: Manchester do Norte, uma alusão à cidade inglesa de Manchester, um dos ber- 
ços da Revolução Industrial. Essa descontinuidade discursiva que move os enunciados São Luís, Atenas Brasileira; São Luís, Manchester do Norte - ancora-os em certas condições de existência. No primeiro momento, o da Atenas Brasileira, há uma valorização da tradição colonial, enquanto no segundo, o da Manchester do Norte, vai haver uma negação dessa tradição, mobilizada pelos ideais de modernidade que ganhavam espaço na capital maranhense.

Essas configurações revelam um conceito de patrimônio cultural que se edifica no campo imaterial, na medida em que diz respeito à cultura e às tradições de um grupo social. A construção da ideia de Atenas Brasileira ocorre num momento de efervescência cultural, de grande produção literária com forte tendência colonial. A construção da Manchester do Norte ancora-se em uma ideia de modernidade, mas vai buscar no passado traços da presença dos franceses, fazendo emergir uma ideologia da singularidade. Essa singularidade, até hoje associada à fundação da capital maranhense, estaria associada também ao discurso da modernidade inaugurado na França.

Portanto, antes mesmo de se cunhar o conceito de "patrimônio" em São Luís, temos nos discursos desse momento a ideia de patrimônio associada ao campo imaterial. Nesse sentido, o conceito de patrimônio decorrente do discurso da Atenas Brasileira configura-se em torno da identidade marcada pelos intelectuais letrados.

Essa ideia tem sido revisitada no discurso oficial como uma estratégia para o desenvolvimento do turismo na capital maranhense. O patrimônio imaterial compreende os bens de caráter processual e dinâmico, ou seja, modos de fazer, costumes e saberes. A construção da Atenas Brasileira compreende os saberes de uma época e traça identidades em São Luís que se reflete na crença dos sujeitos de que a capital é aquela "onde se fala o melhor português", por exemplo, e a população local incorpora essa identidade como mais um elemento atrativo para o turismo local.

Não devemos pensar, entretanto, que a identidade seja construída e destruída linearmente. Ao contrário, as transformações históricas e as mudanças nas representações coletivas não se dão de um momento para outro nem se apagam por passes de mágica. Pela própria natureza complexa das tramas discursivas que as fazem emergir elas permanecem mesmo depois de superadas suas possibilidades históricas. Elas permanecem à espreita, sabedoras da possibilidade de sempre retornarem e dialogarem com novos discursos. Por isso, a concepção de patrimônio imaterial, desenhada pelo discurso da Atenas Brasileira e pelo resgate do passado europeu é muito forte até hoje, como se observa em uma propaganda turística oficial veiculada em 2003 (Figura 1).

Nesta propaganda, chama-nos atenção o enunciado:

"SUBI a ladeira do Desterro como os holandeses, franceses e portugueses que nos amaram na aventura. O cheiro da Terra e o sacrifício de chegar em caravelas nos indicam os caminhos de voltar. Ninguém partiu mas todos voltaram".

(José Sarney - Romancista) 


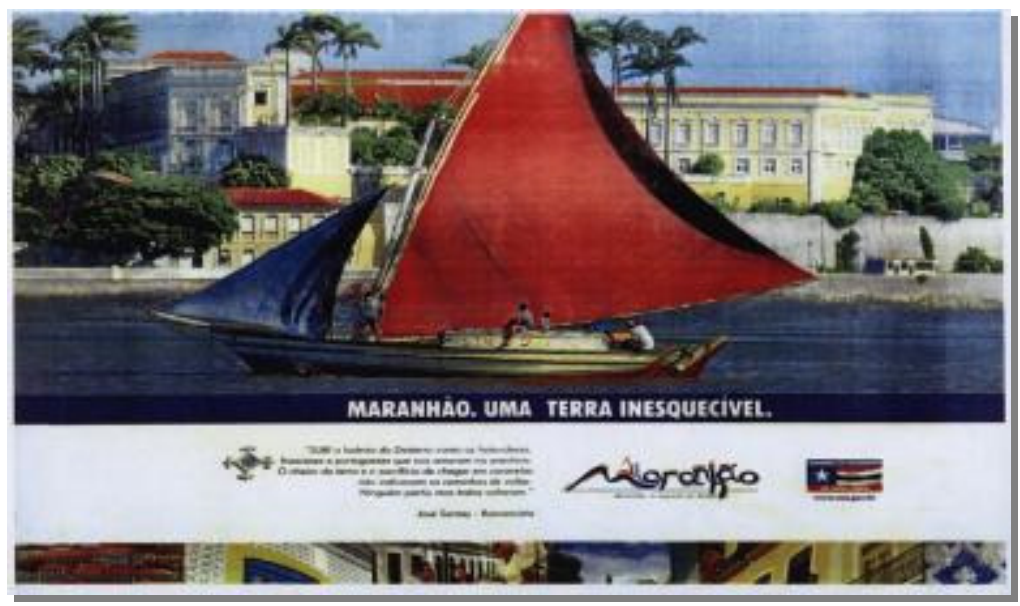

Figura 1: Propaganda turística, Governo do Maranhão, 2003. Fonte: Portal do Governo do Estado. Figure 1: Marketing touristic, Government of Maranhão, 2003. Source: Portal of the State Government.

Para construir o sentido do Maranhão como "terra inesquecível", a propaganda recorre à memória discursiva do passado glorioso, retomando a construção histórica de nossas origens europeias. Ao enumerar "os holandeses, franceses e portugueses que nos amaram na aventura", o texto rememora e reatualiza o mito da Atenas na mesma medida em que apaga outros atores históricos (os indígenas, os africanos escravizados). Ao emergir, em pleno século XXI, esse enunciado reitera, na descontinuidade histórica, uma das identidades maranhenses que as tramas discursivas colaram na memória coletiva.

Segundo Davallon (1999), a memória coletiva só retém do passado o que ainda é vivo ou capaz de viver na consciência do grupo que o mantém. Ela não ultrapassa o limite do grupo. Em São Luís, o grupo de intelectuais (escritores, jornalistas) contribuiu para perpetuar o mito da Atenas Brasileira.

A memória da Atenas Brasileira conserva sua força e atravessa a barreira do tempo deixando sua impressão na memória da comunidade social. Essa memória movimenta a cidade turisticamente, na medida em que há uma ressignificação do espaço. Segundo Coriolano (2009), o turismo se reproduz transformando os espaços em mercadoria, seguindo uma lógica do capital. Essa atividade é uma das principais responsáveis pela produção dos espaços na sociedade contemporânea, agindo no sentido de desterritorializar e produzir novas configurações geográficas. O espaço passa a ser precioso, valorizado.

$\mathrm{Na}$ Figura 2, percebemos o agenciamento de várias identidades. Esse folder reforça a discursividade que constrói a cidade de São Luís como palco da diversidade. O texto verbal destaca e convoca a memória das várias identidades da capital, dentre elas a de Atenas Brasileira e a de Patrimônio Cultural da Humanidade. A enunciação aponta que como cidade Patrimônio Cultural da Humanidade São Luís tornouse um lugar heterotópico, um espaço em que a simultaneidade das identidades acon- 
tece. "É o tudo, ao mesmo tempo, agora", apresentado como o singular da capital maranhense.

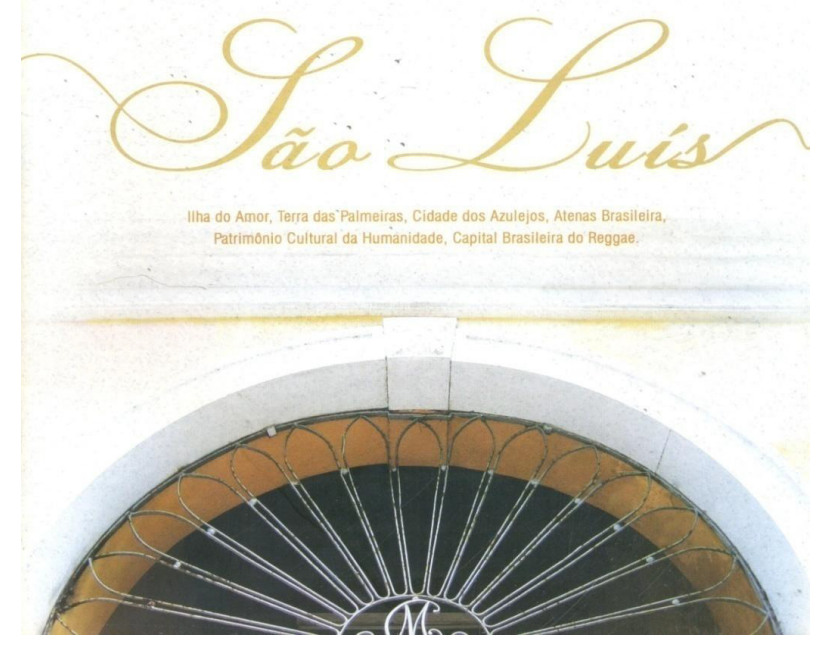

Figura 2: Folder turístico. São Luís, junho 2009. Prefeitura de São Luís. Fonte: São Luís (2009).

Figure 2 - Folder tour. São Luis, June 2009. Prefecture of São Luis. Source: São Luiz (2009).

Dentro da pós-modernidade, devido a uma situação caótica de fragmentação das identidades, da perda de referências gerada por inúmeras transformações nas concepções de tempo e espaço, derivadas, sobretudo, da invenção de novas tecnologias, que aproximaram mundos dantes incomunicáveis, o passado adquiriu muito valor, pois nele estariam as referências de que um povo precisaria para não perder seu "norte". Dessa forma, na cidade de São Luís, as campanhas de patrimonialização direcionaram suas políticas em publicidades que destacam o passado como símbolo de uma memória capaz de sustentar a identidade do povo. Assim, enunciados gerenciados pelo Governo do Estado (governo de Jackson Lago) põem em funcionamento a importância que o passado tem para a elaboração das referências da cidade, ao mesmo tempo em que constroem uma ideia de espaço e promovem sua imagem, destacando as relações de poder que estão imbricadas nesse processo.

Compreender a produção do espaço nesse mercado implica em entendê-lo como uma construção. Ele é, simultaneamente, o lugar das estratégias para o capital e das resistências do cotidiano para os habitantes. A atividade turística é uma das mais recentes modalidades do processo de acumulação, que produz novas configurações geográficas e materializa o espaço de diferentes perspectivas, pela ação do Estado, das empresas, dos residentes e dos turistas.

\section{Considerações finais}

Nossa pesquisa buscou mostrar que, em São Luís, a genealogia do conceito de patrimônio mobiliza várias práticas discursivas. A afirmação de múltiplas singularidades se edifica por meio de um imaginário social, a partir de "um sistema de ideias e imagens" construído pela elite dominante. Nesse processo histórico, vários acontecimentos fazem irromper o conceito de patrimônio. 
Focalizamos o elemento de base dessa genealogia, que é o discurso que se constrói em torno do mito da Atenas Brasileira, que reflete uma visão imaterial de patrimônio, e que se edifica no campo literário, na voz de intelectuais maranhenses. A edificação desse mito se dá a partir de uma tentativa de aproximar os costumes ludovicenses ao de uma cultura erudita. No ambiente cultural que se formou na cidade, destacaram-se dois grupos literários. O primeiro - o Grupo Maranhense - se destacou no cenário nacional e inaugurou uma prática discursiva de exaltação das riquezas e belezas da terra natal, e produziu no segundo grupo - a Segunda Geração - a crença na superioridade do homem maranhense.

Essa identidade e o conceito de patrimônio dela decorrente convivem com outras identidades (Manchester do Norte, Cidade Patrimônio da Humanidade, Capital brasileira do Reggae, dentre outras) e conceitos forjados ao longo da história, dialogando seja pela polêmica, seja pela contratualidade, produzindo relações sociais e espaciais que se transformam no fluxo do tempo. Mas isso não se faz sem conflitos, contradições e resistências. Cada local, região ou país tem sua formação própria, sua cultura, valores e costumes e desse modo o espaço do turismo é produzido conforme essas relações mais amplas, em um processo articulado à produção geral da sociedade.

\section{Referências bibliográficas}

ABRANCHES, D. O Captiveiro. Rio de Janeiro: Jornal do Comércio, Rodrigues \& C, 1941.

ABRANCHES, D. Espelho crítico-político da província do Maranhão. Lisboa: Typ. Rollandianna, 1822.

BERMAN, M. Tudo que é sólido desmancha no ar: a aventura da modernidade. 2. ed. São Paulo: Companhia das Letras, 2007.

CORIOLANO, L.N.M.T. Espaço, poder e turismo: novas configurações geográficas. Disponível em: <http://www.sbpcnet.org.br/livro/57ra/programas/CONF SIMP/textos/ luzianeidecoriolano-reestruturacao.htm>. Acesso em: 18 out. 2009.

FALCON, F.J.C. Iluminismo. 2. ed. São Paulo: Ática, 1989.

FERREIRA, M.V. Reflexões acerca do progresso material da província do Maranhão. Maranhão: Typ. do Frias, 1866.

FOUCAULT, M. O nascimento da medicina social. In: FOUCAULT, M. Microfísica do poder. Organização e tradução de Roberto Machado. 23. ed. Rio de Janeiro: Graal, 2007.

GREGOLIN, M.R. Foucault e Pêcheux na Análise do Discurso. São Carlos: Editora Claraluz, 2004.

GONÇALVES, J.R.S. A retórica da perda: os discursos do patrimônio cultural no Brasil. 2. ed. Rio de Janeiro: UFRJ/ IPHAN, 2002.

LACROIX, M.L. A fundação francesa de São Luís e seus mitos. 3. ed. São Luís: EDUFMA, 2008. 
MARTINS, R.S. Atenienses e fluminenses: a invenção do Cânone Nacional. Anais do Seta, Campinas, v. 2, p. 293-298, 2008. Disponível em: <http://www.iel.unicamp.br/revista/ index.php/seta/article/viewFile/435/361>. Acesso em: 5 mai. 2012.

MARTINS, M.B. Operários da saudade: os novos Atenienses e a invenção do Maranhão. São Luís: EDUFMA, 2006.

MEIRELES, M.M. História do Maranhão. 4. ed. Imperatriz: Ética, 2008.

PESAVENTO, S.J. História e História Cultural. Belo Horizonte: Autêntica, 2004.

RAMA, A. A cidade das letras. São Paulo: Brasiliense, 1985.

REIS, F.A.C. Cartas a um velho amigo: ligeiro estudo sobre o estado econômico e industrial do Maranhão. Rio de Janeiro: Tipografia de Domingos Luiz dos Santos, 1877.

SARGENTINI, V.; NAVARRO-BARBOSA, P. (Orgs.). Foucault e os domínios da linguagem: discurso, poder, subjetividade. São Carlos: ClaraLuz, 2004.

Notas:

${ }^{1}$ Outras cidades brasileiras como Fortaleza, Olinda, Recife, Salvador, Rio de Janeiro receberam, também, ao longo do século XIX, o cognome de "Atenas Brasileira". Esse cognome era atribuído sempre que um grupo de intelectuais e literatos desenvolvia um volume de atividades culturais e literárias, tais como publicações, polêmicas e eventos que engrossavam as fileiras do nascente mundo literário e cultural dos oitocentos brasileiros (MARTINS, 2008).

${ }^{2}$ A ideia que constrói o conceito de cidade letrada se fundamenta na participação de intelectuais e letrados na construção e consolidação da sociedade latino-americana desde a conquista ibérica até o início do século XX, com o propósito de relacioná-los ao campo do poder (RAMA, 1985).

Conceição de Maria Belfort Carvalho: Universidade Federal do Maranhão, São Luis, MA, Brasil.

Email: cbelfort@globo.com

Link para o currículo Lattes: http://lattes.cnpq.br/7821541616565704

Data de submissão: 24 de maio de 2012

Data de recebimento de correções: 09 de janeiro de 2013

Data do aceite: 11 de junho de 2013

Avaliado anonimamente 